\title{
AC 2008-1309: THE DEVELOPMENT OF A GEL FUEL PROCESSING SYSTEM FOR USE IN RURAL GHANA
}

Bradley Rogers, Arizona State University

Mark Henderson, Arizona State University

Jerry Gintz, Arizona State University

Scott Danielson, Arizona State University 


\section{The Development of a Gelfuel Processing System for use in Rural Ghana}

Smoke from cooking fires is one of the most serious health issues in the developing world, destroying the health of women and killing more than 2 million children per year. Worldwide, acute respiratory disease is the number one cause of death for children under 5, and has be traced to the high levels of smoke generated by cooking fires in developing countries. Furthermore, the once abundant resource is becoming scarce, so that in many cases women must travel large distances on foot to gather the wood they need, an effort that occupies much of their day. One solution is to change fuels and cook with gelled ethanol created from locally available biomass. This is the purpose of the gelled ethanol production unit which was being built by 13 students in the Capstone design sequence in the Mechanical and Manufacturing Engineering Technology Department on the Polytechnic campus of Arizona State University, and which will be described in this paper.

For this project, ASU has partnered with the Kwame Nkrumah University of Science and Technology in Kumasi, Ghana and with the rural village of Domeabra, in the Ashanti region of Ghana. The prototype machine is scheduled to be delivered to the village in the spring of 2008, and the chief and elders of the village have planted approximately 20 acres of corn to process in to gelfuel.

The project described in this paper is part of a larger interdisciplinary initiative at ASU known as GlobalResolve, in which entrepreneurial models for economic progress in developing countries are pursued. This leads to unique design constraints on projects that result in very rewarding experiences for the students that are involved. 